\title{
Analysis of Customer Behavior Using Web Usage Mining
}

\author{
Mamman Ojima John ${ }^{1} \quad$ Onoja Emmanuel Oche ${ }^{2} \quad$ Onah John Oche ${ }^{2}$ \\ 1.Department of Mathematics/Statistics/Computer Science Federal University of Agriculture Makurdi, Nigeria \\ 2.Department of Cyber Security Science, Federal University of Technology Minna, Nigeria
}

\begin{abstract}
This paper attempts to figure out the concealed data and establish user behavior online by exploiting the online as a source for data collection. With the assistance of this information, user behavior can be predicted very easily. Free tool like similar web and page score were used to analyze user pattern on the web site of the particular establishment. These tools attempt to conduct mining on the web in an independent manner. The experimental result emphasizes a clear way to surf through the web and enhance the design of the web. This paper discusses the elaborate results of website in a particular education domain application. The main objective of conducting this study on websites of the different polytechnics in Federal Republic of Nigeria is to discern the pattern of behavioral expressions and user characteristics so that institutional establishments can enhance their website structure and may transfer additional information in an applicableand timely manner.
\end{abstract}

Keywords: Customer Behavior; Web usage mining; similar web; Page Score; Pattern.

DOI: $10.7176 / \mathrm{IKM} / 10-6-02$

Publication date:September $30^{\text {th }} 2020$

\section{INTRODUCTION}

Customer relationship is a key application when mining the web. Internet mining involves a large variety of applications that aims at discovering and extracting concealed data [1] stored on the web. A web site ought to be designed to lure the client. Web Mining explores client's behavioral pattern and predicts their future interaction. These predictions can be used to enhance the website and to recommend products based on clients' preference. Customer surfing through the web exhibits different behavioral pattern. They could simply surf through or they might end up in a purchase, in addition to retaining existing customers, predicting client purchase behavior encourages improvement of services and profit increase [7]. For understanding customer behavior and thus improve the performance of your web site, sure standards ought to be used like perform mining on diary information that essentially record visitors' browsing behavior within the history [6] and collect data from the shopper aspect, the server aspect, and therefore the agent within the diary. The basic idea concerning the Web is that the server makes resources available to customer all over on the Internet, the whole system is meaningless without any resource. As a consequence, business analysts need to grasp and understand customers' behavior when they navigate through the website, still as making an attempt to spot the explanations that impelled them to get, or to not purchase a product [2]. This data include various logs and transaction details and with this information, market analyses and predictions can be done very fairly accurately thereby retaining customers [3]. This can be owing to the promoting conception, institutions will improve their web site services and productivity, and in turn increase their potential customers, and also aware of the action of the purchasers after they browse their websites [4].

\section{DATA MINING}

Data is been collected, processed and then cleaned when mining technique is used to extract information from the big net logs. Which are often automated and systematic process of analysis of emerging information and users' behavioral patterns. Considering the voluminous information, it's significantly difficult to venture into all details of users of the online.

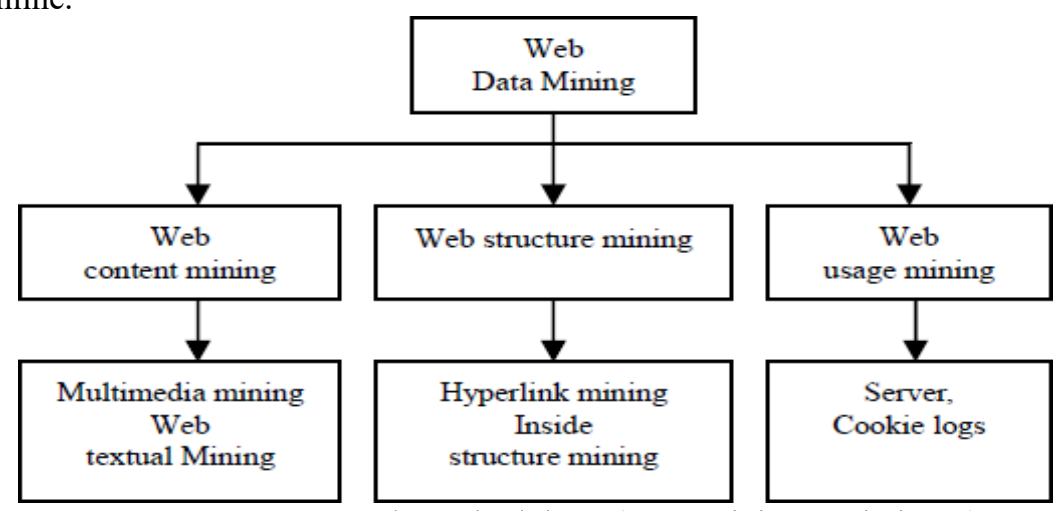

Figure 1: Research Methodology (Data Mining Techniques) 


\section{A. Web Content Mining}

Web content mining is the method of finding and extracting information from a huge quantity of collected net information. This method may be classified into text mining and multimedia system mining. Website mining involves re-processing to get additional correct and helpful information query results from an enquiry engine. The semi-structured net information are reconstructed to a more structured information, so the quality information query mechanism and therefore the methodology of mining may be used for analysis. An outline of page, classification, clustering, and association rules may be found once mining hypertext mark-up language page content using text mining to the text on the page or using multimedia system data processing to the multimedia system information on the page.

\section{B. Web Structure Mining}

Web structure mining essentially finds potential web link structure model. It can work by deriving knowledge from the organizational and link relationship on the www, analyzing the webpage link visited by the user, analyzing the number of links and link objects, and creating their own web link structural mode. This model can be used for web page classification, and then the similarity and therefore the relationship to access the information between completely different pages can be found to analyze the rules of web pages related to the subject.

\section{Web Usage Mining}

Customers' business activities and their browsing information on a website are recorded in a log file. Web usage mining analyzes the web page browsing model of customers and finds the information of potential customers according to the server's log files, which are used to understand and handle customers' web behavior.

The web site structure may be improved once client behavior is known. Two types of tracking area exist: general access pattern tracking and personal usage records tracking. General access pattern tracking is used for improving the website institutions structure on understanding customers' access patterns and trends. Personal usage records tracking analyzes the preferences of individual customers and provides customized websites for different customers, betting on their access patterns [5].

\section{MATERIALS AND METHODS}

Data is collected by using free web analyzer tools. A comparative study is created between indiscriminately chosen polytechnics from Federal Republic of Nigeria by knowing the client interaction between the period 7 December 2017 to 31 October 2018 on the web sites of the polytechnics mentioned in table 1 by using similar web tool and page score tool. Variety of experiments is accessible to investigate these net server access logs as an input. It generates the reports for frequent access and identifies the user access patterns.

\section{A. Tables and Figures}

Table 1: Shows the Polytechnics name and its code which is temporary assigned for experimental purposes

\begin{tabular}{|c|l|}
\hline Code Name & \multicolumn{1}{c|}{ Polytechnics Name } \\
\hline A & Abraham Adesay Polytechnic Ijebu Igbo Ogu State \\
\hline B & Imo State Polytechnics, Umugwo, Ohaji Imo State \\
\hline C & Shaka Polytechnic Benin City, Edo State \\
\hline D & NACABS Polytechnics Akwanga, Nasarawa State \\
\hline E & The Polytechnic, Imesi-Ile Osun Nasarawa State \\
\hline F & The Polytechnic, Adoka, Otada, Benue State. \\
\hline G & Kalac Crystal The Polytechnic, Lekki, Lagos State \\
\hline H & Akwa Ibom State The Polytechnic Ikot Osurua, Akwa Ibom \\
\hline
\end{tabular}

Table 2: this table offers comparative Country Ranking and state ranking of the Polytechnics Analysis Report from similar web and page score.

\begin{tabular}{|c|c|c|}
\hline & \multicolumn{2}{|c|}{ Ranking } \\
\hline Code Name & Country & State \\
\hline A & 84 & 6 \\
\hline B & 25 & 6 \\
\hline C & 81 & 4 \\
\hline D & 81 & 8 \\
\hline E & 62 & 4 \\
\hline F & 103 & 6 \\
\hline G & 109 & 7 \\
\hline H & 99 & \\
\hline
\end{tabular}


Table 3: This table shows how many visitors visit the websites of the Polytechnics on portable and Desktops to seek out information.

\begin{tabular}{|c|c|}
\hline Code & Total Visit \\
\hline A & $43.20 \mathrm{~K}$ \\
\hline B & $435.90 \mathrm{k}$ \\
\hline C & $62.15 \mathrm{k}$ \\
\hline D & $115.61 \mathrm{k}$ \\
\hline E & $459.20 \mathrm{k}$ \\
\hline F & $27 \mathrm{~K}$ \\
\hline G & $6.80 \mathrm{k}$ \\
\hline H & $40.10 \mathrm{k}$ \\
\hline
\end{tabular}

Table 4: This table shows loading time once a client browses the website of selected polytechnic.

\begin{tabular}{|c|c|}
\hline Code. & Loading Time (in Sec) \\
\hline A & 5.64 \\
\hline B & 32.15 \\
\hline C & 29.22 \\
\hline D & 79.47 \\
\hline E & 18.02 \\
\hline F & 59.12 \\
\hline H & 72.17 \\
\hline
\end{tabular}

Table 5: This table shows the traffic sources utilized by the client to succeed in a selected web site of aforementioned polytechnic.

\begin{tabular}{|l|l|l|l|l|l|}
\hline Code. & Direct & Referrals & Search & Social & Mail \\
\hline A & $15.00 \%$ & $5.36 \%$ & $76.64 \%$ & $1.15 \%$ & $1.85 \%$ \\
\hline B & $30.50 \%$ & $7.08 \%$ & $60.57 \%$ & $0.68 \%$ & $1.17 \%$ \\
\hline C & $20.28 \%$ & $4.51 \%$ & $71.98 \%$ & $3.23 \%$ & $0.00 \%$ \\
\hline D & $29.38 \%$ & $10.05 \%$ & $60.30 \%$ & $0.27 \%$ & $0.00 \%$ \\
\hline E & $56.03 \%$ & $5.72 \%$ & $35.93 \%$ & $1.52 \%$ & $0.80 \%$ \\
\hline F & $15.54 \%$ & $7.09 \%$ & $75.45 \%$ & $1.92 \%$ & $0.00 \%$ \\
\hline G & $33.71 \%$ & $13.99 \%$ & $51.65 \%$ & $0.63 \%$ & $0.02 \%$ \\
\hline H & $26.10 \%$ & $2.30 \%$ & $70.70 \%$ & $0.90 \%$ & $0.00 \%$ \\
\hline
\end{tabular}

\section{RESULTS AND FINDINGS OF ANALYSIS}

This paper used the information collected from the online Sites of some Polytechnics in Federal Republic of Nigeria from 7 December 2017 to 31 October 2018. This collected data is analyzed by using Different free Tools Such as Similar web and Page Score. The whole experimental analysis was done on the idea of diary information of the tutorial Polytechnics web site and a comparative analysis report is ready. The look and execution of such work is restricted and time overwhelming. Comparative chart of instructional websites of polytechnics is given below:

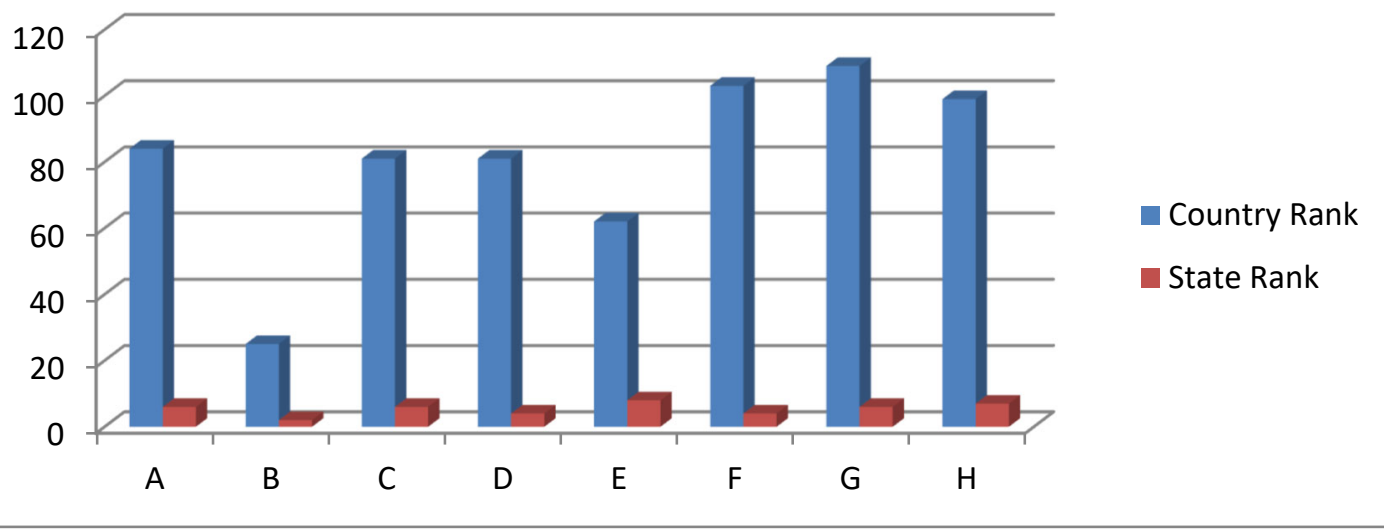

Figure 2: Country and State ranking of Polytechnics 


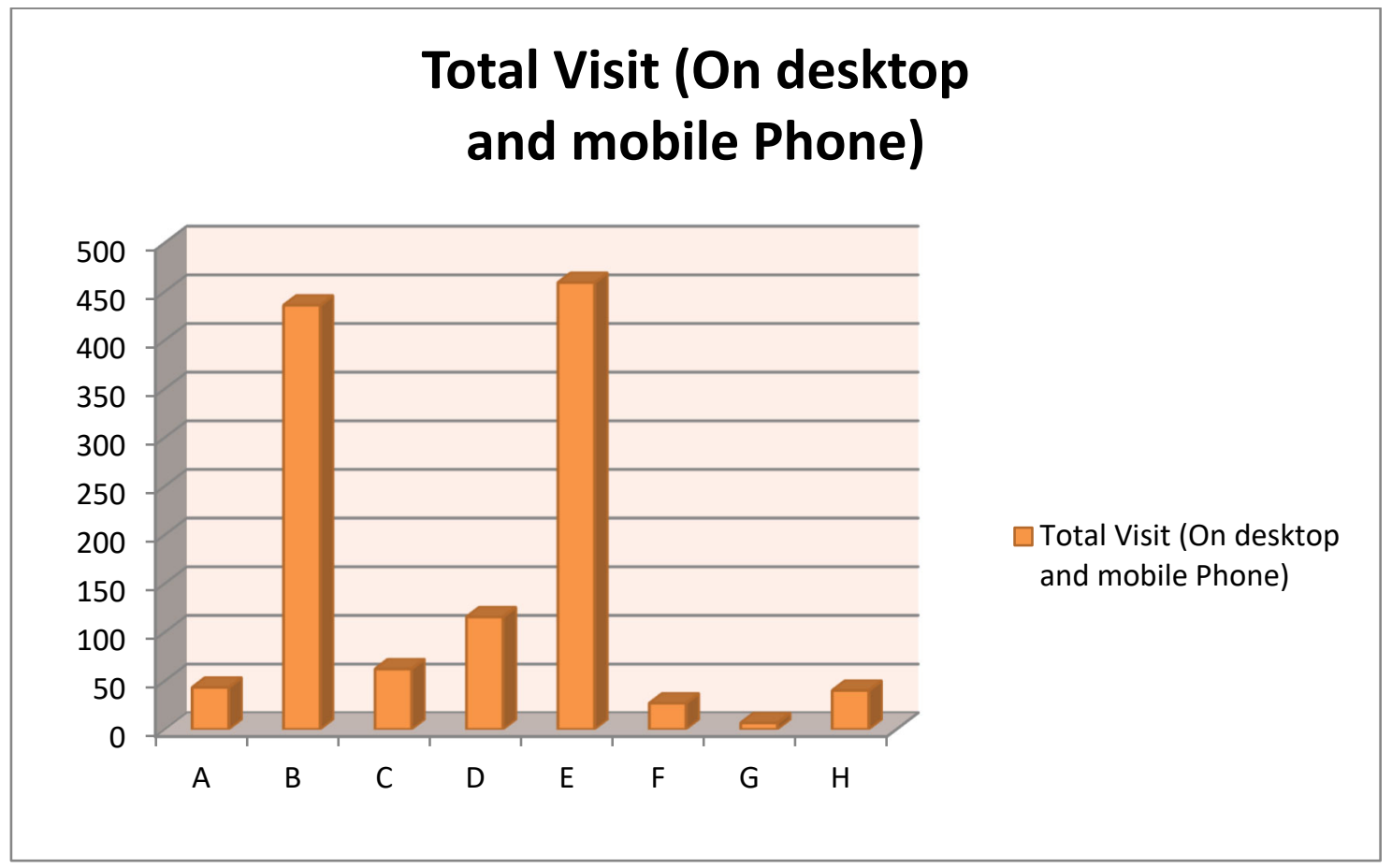

Figure 3: Shows the total number of visitors on a particular polytechnic website within a time period

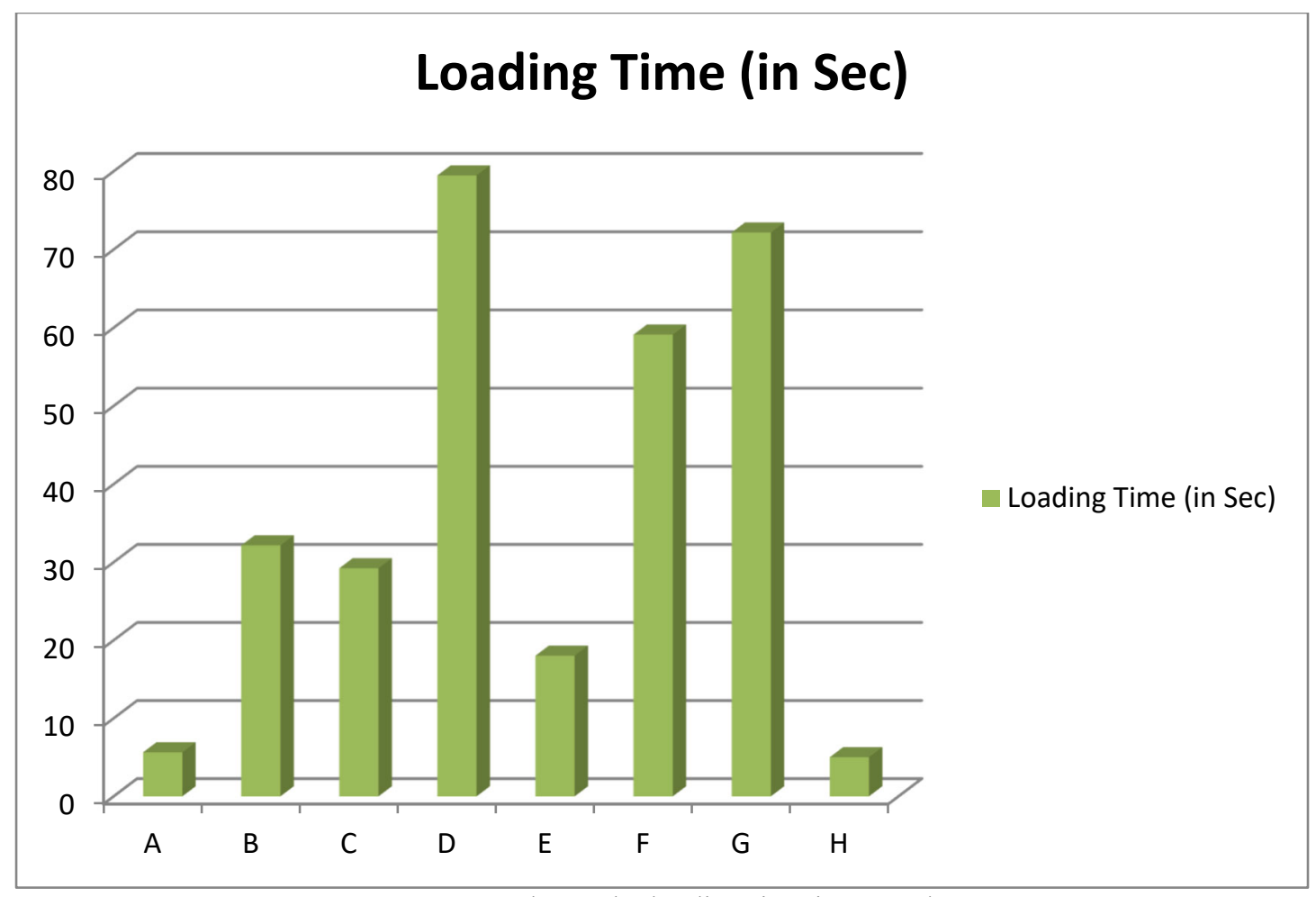

Figure 4: Shows the loading time in seconds 


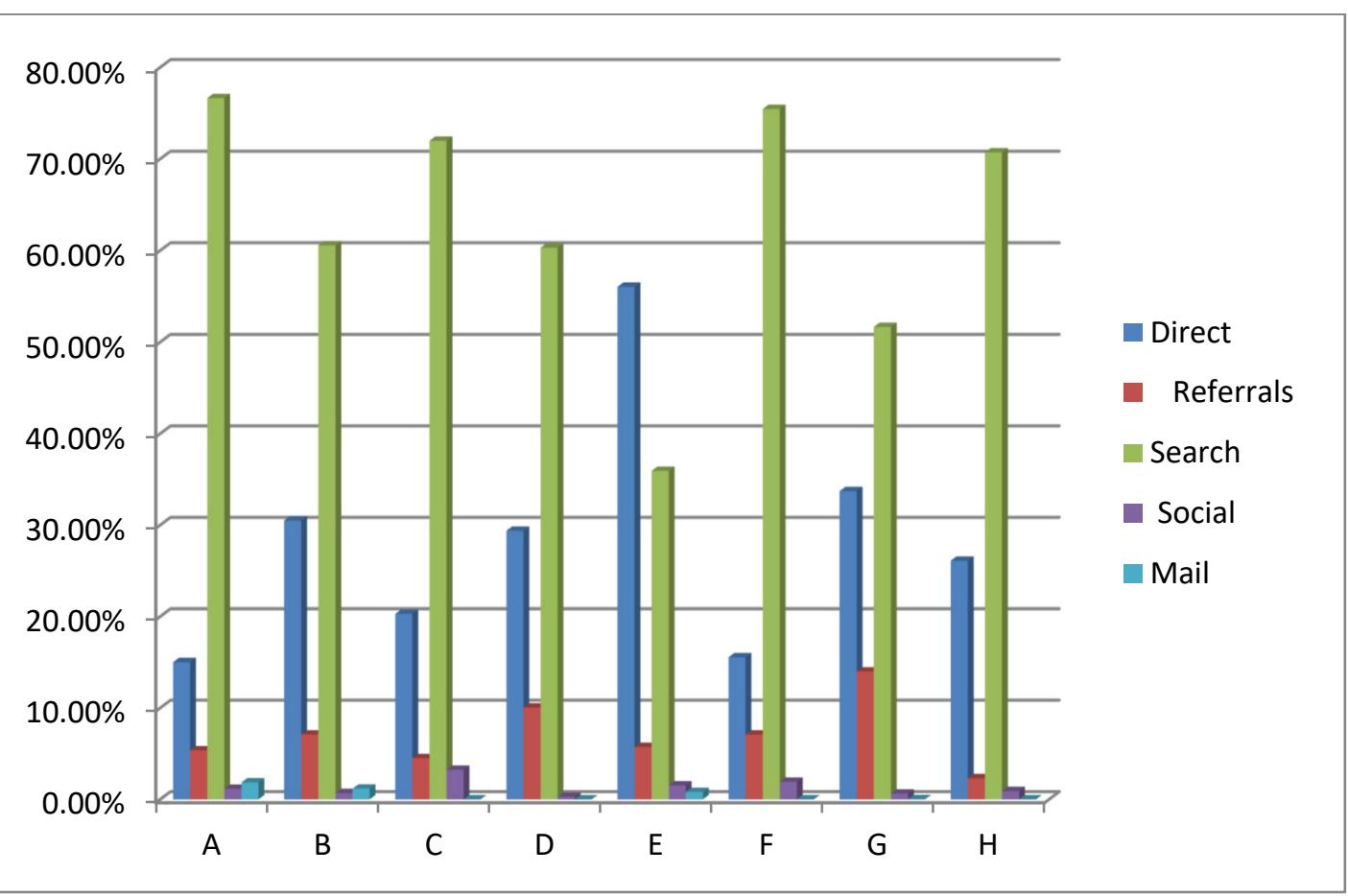

Figure 5: Shows the traffic sources used by the client to access a selected web site of a polytechnic.

\section{DISCUSSION}

From 7 December 2017 to 31 October 2018 Figure 3 clearly shows that Polytechnic code E which is the Polytechnic, Imesi-Ile Osun State, Country and State ranking approaches that maximum customer visit to their Polytechnic website as compared to other Polytechnics. Website loading time of Polytechnic H i.e. Akwa Ibom state polytechnic Ikot Osurua, Akwa Ibom is less as compared to other polytechnics. 459.20K customers visit the Polytechnic, Imesi-Ile Osun State website during December 2017 to October 2018. The application of web mining to educational domain has many benefits. The business environment keeps on moving forward, and customer's cogitation are modified, particularly in terms of various strategies of accessing information or buying. Some educational institutions still operate in the same place and refuse to accept new technology. To increase the capacity to make profit and augment the service provided to the customer (students), understanding client behavior is crucial for establishments to maneuver forward to the longer-term business opportunities, and establishments can effectively know the action of the customers when they browse their websites [8].

\section{CONCLUSIONS}

The practical significance of web mining is evident in an increase of tremendous use of website for educational purposes and online purchasing and for everything which a customer wants with the click of a mouse, web usage mining is one of the important research areas through which browsing and navigation of data can easily be predicted. There are several methods and tools suggested by different researchers for the web usage mining. This paper focuses on educational domain web user pattern discovery and pattern analysis using similar web and page score. The results obtained ought to fully facilitate the web site Analysts, Maintainers and Designers.

\section{REFERENCES}

[1] Chakrabarti, S. 'Mining the web discovering knowledge form hypertext data' San Francisco. CA. Morgan Kaufmann Publishers An imprint of Elsevier Science pp 1-13 (2003).

[2] Liu G., Nguyen T. T., Zhao G., Zha W., Yang J., Cao J., Wu M., Zhao P., and Chen W. 'Repeat buyer prediction for e-commerce' in Proceedings of the 22Nd ACM SIGKDD International Conference on Knowledge Discovery and Data Mining, ser. KDD '16. New York, NY, USA: ACM, , pp. 155-164 (2016).

[3] $\mathrm{Xu}, \mathrm{J}$. D. 'Retaining customers by utilizing technology-facilitated chat: Mitigating website anxiety and task complexity’ Information \& Management,53(5):554 - 569 (2016).

[4] Sharma P. and Kumar S. 'An Approach for Customer Behavior Analysis Using Web Mining' International Journal of Internet Computing, ISSN: 2231-696, Issue-2 (2011).

[5] Zihao S. and Wang H. 'Research on E-Commerce Application Based on Web Mining' Intelligent Computing and Cognitive Informatics (ICICCI), International Conference on, vol., no.:3(1), pp.: 22-23 June (2010). 
[6] Yadav, M. P., Feeroz, M. and Yadav, V. K. 'Mining the customer behavior using web usage mining in ecommerce' Computing Communication \& Networking Technologies (ICCCNT), Third International Conference on, vol., no.: 5(1), pp.: 26-28 July (2012).

[7] Tang, H., Yan, H., Zengfang Y., Yu M. and Chunping L. 'Application of Data Mining in Electronic Commerce' Information Engineering, 2009. ICIE '09. WASE International Conference on, 1(3), pp.: 10-11 July (2009).

[8] Sharma P. and Kumar S. 'An Approach for Customer Behavior Analysis Using Web Mining' International Journal of Internet Computing, ISSN: 2231-696, Issue-2 (2011). 